\title{
Effect of Counteranions on the Conformational Equilibrium of 1-Butyl-3-methylimidazolium-Based Ionic Liquids
}

\author{
Naohiro Hatano, ${ }^{1}$ Takahiro Takekiyo, ${ }^{1}$ Hiroshi Abe, ${ }^{2}$ and Yukihiro Yoshimura ${ }^{1}$ \\ ${ }^{1}$ Department of Applied Chemistry, National Defense Academy, 1-10-20 Hashirimizu, Yokosuka, Kanagawa 239 8686, Japan \\ ${ }^{2}$ Department of Materials Science and Engineering, National Defense Academy, 1-10-20 Hashirimizu, Yokosuka, \\ Kanagawa 239-8686, Japan
}

Correspondence should be addressed to Takahiro Takekiyo, take214@nda.ac.jp

Received 13 July 2011; Accepted 13 September 2011

Academic Editor: Rolf W. Berg

Copyright (c) 2011 Naohiro Hatano et al. This is an open access article distributed under the Creative Commons Attribution License, which permits unrestricted use, distribution, and reproduction in any medium, provided the original work is properly cited.

We have investigated the nonspherical anion effect on the trans-trans (TT) and gauche-trans (GT) equilibrium in pure 1-butyl-3methylimidazolium $\left([\mathrm{bmim}]^{+}\right.$)-based room temperature ionic liquids (RTILs) by the Raman spectroscopy. The intensity ratio of the $[\mathrm{bmim}]^{+}$cation in $[\mathrm{bmim}]^{+}$-based RTILs having nonspherical anions changes with nature of the anions. However, the enthalpy change of the $[\mathrm{bmim}]^{+}$cation is approximately $-1.0 \mathrm{~kJ} / \mathrm{mol}$ for all $[\mathrm{bmim}]^{+}$-based RTILs used in this study and is independent of the anionic species. The present results indicate that the conformational stability of the $[\mathrm{bmim}]^{+}$cation in $[\mathrm{bmim}]^{+}$-based RTILs including nonspherical anions is driven by the entropic contribution associated with the orientation and configuration of the $[\text { bmim }]^{+}$cation with respect to the counteranion.

\section{Introduction}

Room temperature ionic liquids (RTILs) consisting of organic cations and anions remain in the liquid state at room temperature [1]. The conformational behavior of RTILs has been studied to identify correlations with chemical and physical properties of RTILs, such as conductivity, viscosity, and melting point $[1-5]$.

The conformational equilibria of imidazolium cations, such as 1-ethyl-3-methylimidazolium and 1-butyl-3-methylimidazolium $\left([\mathrm{emim}]^{+}\right)$of the imidazolium-based RTILs, the so-called prototype ionic liquids, have been investigated by the Raman spectroscopy combined with density functional theory calculations $[2,5-12]$. The $[\mathrm{bmim}]^{+}$cation has a trans-trans and gauche-trans (TT-GT) equilibrium for NCCC and CCCC angles of the butyl group, as shown in Figure 1. Thermodynamic studies of the conformational equilibrium of RTILs are useful to clarify the relationship between the conformation and the complicated phase transition behavior of these RTILs [3-5].

The effect of spherical anions, such as halide anions $\left(\mathrm{Cl}^{-}, \mathrm{Br}^{-}\right.$, and $\left.\mathrm{I}^{-}\right)$, on the TT-GT equilibrium of the $[\mathrm{bmim}]^{+}$cation in pure $[\mathrm{bmim}]^{+}$-based RTILs has been studied [3, 10-12]. Katayanagi et al. [3] reported that the conformational preference of the $[\mathrm{bmim}]^{+}$cation varies with different halide anions. In relation to this, using the Raman spectroscopy and molecular dynamics (MD) simulations, Umebayashi et al. [12] showed that the thermodynamic stability of the conformational equilibrium of the [bmim $]^{+}$ cation is affected by the halide anion. Important conclusion is that anions localized near the $\mathrm{C} 2-\mathrm{H}$ atoms of the $[\mathrm{bmim}]^{+}$ cation stabilize the gauche conformer, and the effect is stronger with smaller anions. On the other hand, Lopes and Pádua [13] reported that the populations of the conformers of the $[\mathrm{bmim}]^{+}$cation in $[\mathrm{bmim}][X]\left(X=\mathrm{BF}_{4}, \mathrm{PF}_{6}\right.$, or TFSA, i.e., other than the halide anions) are nearly independent of the associated anions by a molecular simulation. In this situation, we feel that a general view of the effect of counteranions on the conformational equilibrium of the $[\mathrm{bmim}]^{+}$cation has not been established yet.

In this study, we have investigated the thermal stability of the $T T-G T$ equilibrium of the $[\mathrm{bmim}]^{+}$cation in pure [bmim] $[X]$ RTILs $\left(X=\mathrm{CH}_{3} \mathrm{COO}, \mathrm{SCN}, \mathrm{NO}_{3}, \mathrm{BF}_{4}\right.$, and $\mathrm{PF}_{6}$ ) including nonspherical anions using the Raman spectroscopy to help a further understanding of the dependence of the conformational isomerism in $[\mathrm{bmim}]^{+}$-based ionic 


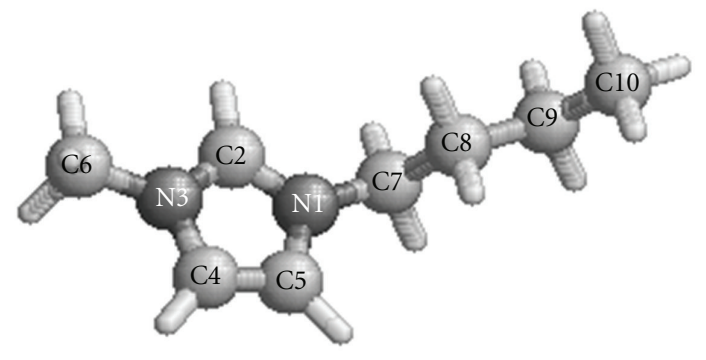

(a) Trans-Trans (TT) conformer

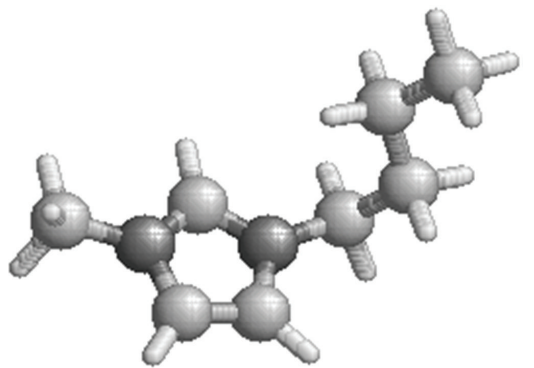

(b) Gauche-Trans (GT) conformer

FIGURE 1: Optimized structures of the (a) trans-trans (TT) and (b) gauche-trans $(G T)$ conformers of 1-butyl-3-methylimidazolium $\left([\mathrm{bmim}]^{+}\right)$cation by B3LYP/6-311+(d) level.

liquids on the nature of the anion. Our results showed that the conformational preference of the $[\mathrm{bmim}]^{+}$cation varies with different counteranions studied, and the conformational stability is entropically (configuration) driven.

\section{Experimental}

In this study, as samples we selected RTILs 1-butyl-3-methylimidazolium acetate $\left([\mathrm{bmim}]\left[\mathrm{CH}_{3} \mathrm{COO}\right]\right)$, thiocyanate $([\mathrm{bmim}][\mathrm{SCN}])$, nitrate $\left([\mathrm{bmim}]\left[\mathrm{NO}_{3}\right]\right)$ (these are purchased from Aldrich), tetrafluoroborate ([bmim] $\left[\mathrm{BF}_{4}\right]$ ) and hexafluorophosphate $\left([\mathrm{bmim}]\left[\mathrm{PF}_{6}\right]\right)$ (purchased from Kato Chemical Co). Just in case, water contents in the samples were checked by a Karl-Fischer titration method and found to be less than $120 \mathrm{ppm}$. Generally, RTILs are easily contaminated by vacuum drying to reduce $\mathrm{H}_{2} \mathrm{O}$; thus, we used the samples without further purification, and special care was taken to avoid further atmospheric contamination.

The Raman spectra were measured by a JASCO NR-1800 Raman spectrophotometer equipped with a single monochromator and a charge-coupled device detector. The exposure time for each run and the spectral resolution were $3.0 \mathrm{~s}$ and $8.6 \mathrm{~cm}^{-1}$, respectively. The $514.5 \mathrm{~nm}$ line for [bmim] $[X]\left(X=\mathrm{BF}_{4}\right.$ and $\left.\mathrm{PF}_{6}\right)$ and the $647.1 \mathrm{~nm}$ line for $[\mathrm{bmim}][X]\left(X=\mathrm{CH}_{3} \mathrm{COO}, \mathrm{SCN}\right.$, and $\left.\mathrm{NO}_{3}\right)$ from Lexel $\mathrm{Ar}^{+}$and $\mathrm{Kr}^{+}$ion lasers were used as excitation sources with a power of $250 \mathrm{~mW}$. For thermal conformational variation experiments, the temperature was increased from $273 \mathrm{~K}$ to $368 \mathrm{~K}$ in $10 \mathrm{~K}$ increments using a Japan High-Tech LK$600 \mathrm{PH}$ temperature controller. The resulting Raman spectra were fitted with Gaussian-Lorentzian mixing functions using the GRAMS/386 software (Galactic Ind. Co. Ltd.).

\section{Results and Discussion}

Figure 2 shows the Raman spectra in the region from 530 to $680 \mathrm{~cm}^{-1}$ of pure [bmim] $[X]\left(X=\mathrm{CH}_{3} \mathrm{COO}, \mathrm{SCN}, \mathrm{NO}_{3}\right.$, $\mathrm{BF}_{4}$, and $\left.\mathrm{PF}_{6}\right)$ at $298 \mathrm{~K}$. The vibrational assignments of the Raman bands in this region for pure [bmim] $]^{+}$-based RTILs were well established $[2,6,7]$. According to previous studies $[2,7]$, the Raman bands at 600 and $620 \mathrm{~cm}^{-1}$ arising from the $\mathrm{CH}_{2}$ rocking mode of the NCCC of these RTILs were assigned to the GT and TT conformers of the [bmim] ${ }^{+}$

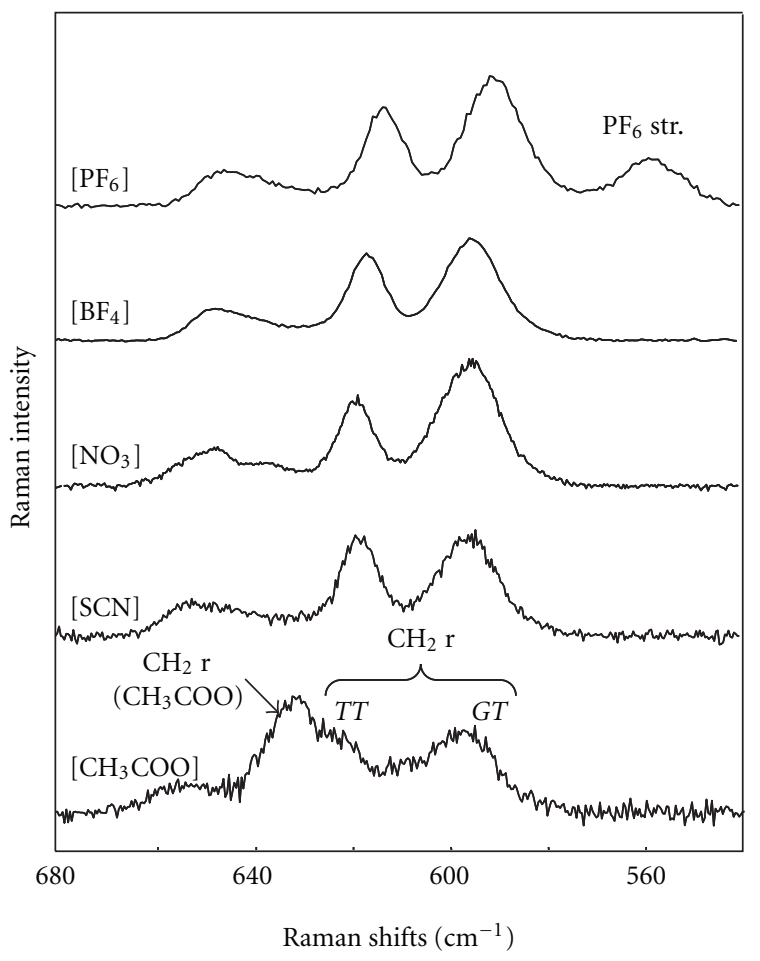

FIGURE 2: The Raman $\mathrm{CH}_{2}$ rocking spectra of pure [bmim] $[X](X=$ $\mathrm{PF}_{6}, \mathrm{NO}_{3}, \mathrm{BF}_{4}, \mathrm{SCN}$, and $\mathrm{CH}_{3} \mathrm{COO}$ ) at $298 \mathrm{~K}$. The " $\mathrm{CH}_{2} \mathrm{r}$ " and " $\mathrm{PF}_{6}$ str" represent the $\mathrm{CH}_{2}$ rocking mode and $\mathrm{PF}_{6}$ stretching mode, respectively.

cation. Using these assignments, we discuss the effect of counteranions on the TT-GT equilibrium of the [bmim $]^{+}$ cation in $[\mathrm{bmim}][X]\left(X=\mathrm{CH}_{3} \mathrm{COO}, \mathrm{SCN}, \mathrm{NO}_{3}, \mathrm{BF}_{4}\right.$, and $\mathrm{PF}_{6}$ ) with a special interest in whether the nonspherical anions induced a change in the Raman intensities of the $\mathrm{CH}_{2}$ rocking mode of the [bmim $]^{+}$cation.

To show detailed conformational changes for the $[\mathrm{bmim}]^{+}$cation, we determined the intensity ratio $\left(I_{G T} / I_{T T}\right)$ of the two conformations of the $[\mathrm{bmim}]^{+}$cation. Because the observed Raman band intensity $(I)$ is proportional to the product of the Raman cross-section $(\sigma)$ and the concentration of the conformer $(c)(I \propto \sigma c)$ [14], the change in $I_{G T} / I_{T T}$ of the $[\mathrm{bmim}]^{+}$cation as a function of the anionic 


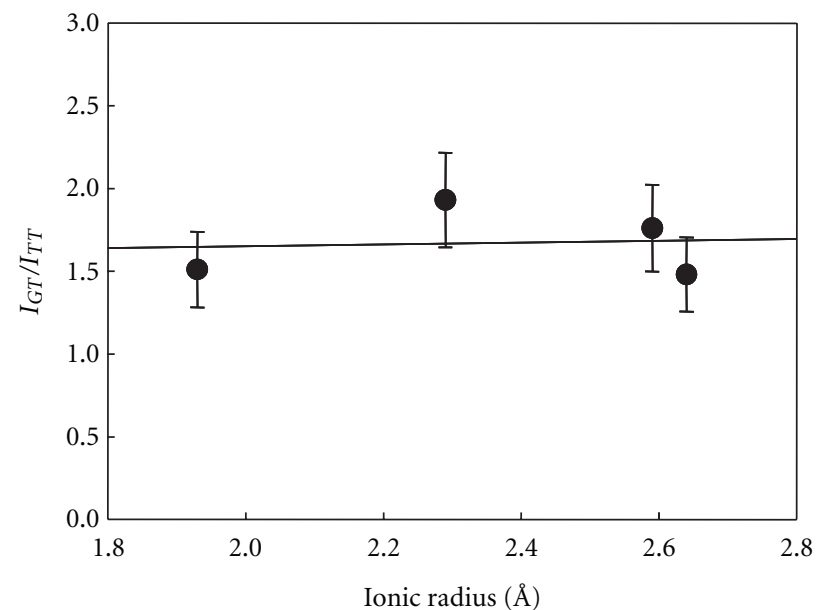

(a)

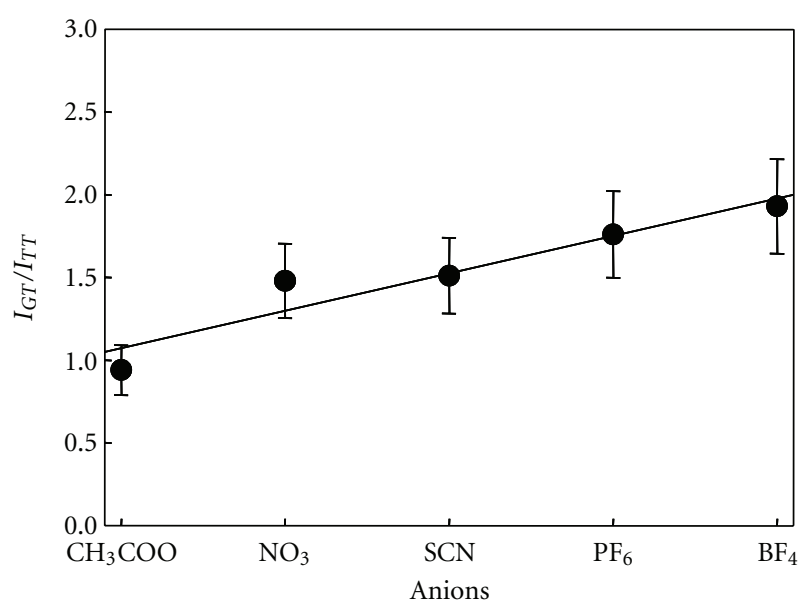

(b)

FIGURE 3: Plots of $I_{G T} / I_{T T}$ of the [bmim] ${ }^{+}$cation versus (a) ionic radius of anions except the $\mathrm{CH}_{3} \mathrm{COO}$ anion, and (b) the order of $I_{G T} / I_{T T}$ for anions of pure $[\mathrm{bmim}][X]\left([\mathrm{X}]=\mathrm{CH}_{3} \mathrm{COO}, \mathrm{NO}_{3}, \mathrm{SCN}, \mathrm{PF}_{6}\right.$, and $\left.\mathrm{BF}_{4}\right)$.

species corresponds to the change in the difference in Gibbs's free energy between the two conformers $(\Delta G)$, which can be represented as $-R T \ln \left(c_{G T} / c_{T T}\right) \quad\left(c_{G T}\right.$ and $c_{T T}$ are the concentration of GT and TT conformers). In the previous study by Katayanagi et al. [3], the Raman intensity of the $T T$ conformer generally increased as the ionic radius of the spherical halide anion increased, while that of the GT conformer decreased. We checked the relationship between the values of intensity ratio $\left(I_{G T} / I_{T T}\right)$ and the ionic radius of anions as shown in Figure 3(a). However, the $I_{G T} / I_{T T}$ of $[\mathrm{bmim}]^{+}$-based RTILs used in this study is less dependent on the ionic radius of anions. Then, the values of intensity ratio $\left(I_{G T} / I_{T T}\right)$ are plotted in order of their values in Figure 3(b). Interestingly, we have found that $I_{G T} / I_{T T}$ seems to be related to the Hofmeister series of anions [15-18], which was originally an indication of the effects of ions on the water structure, although the order of the $I_{G T} / I_{T T}$ values is not perfectly match with the Hofmeister series of anions, that is, at the $\mathrm{BF}_{4}$. Unfortunately, there has been no conclusive idea on the origin of the Hofmeister series. Recently Zhang and Cremer [16] insisted that changes in bulk water structure by added salts cannot explain specific ion effects. Hofmeister phenomena need to be understood in terms of direct interactions between the ions and macromolecules, in addition to the ability of the ions to stabilize the structure of proteins. At any rate, the molecular-level pictures of the Hofmeister phenomena for example, how ions operate, are important, because of their relevance to a broad range of fields [18]. In view of the results, it looks like the Raman intensity of the GT conformer was higher than that of the TT conformer when a relatively chaotropic anion such as $\mathrm{PF}_{6}{ }^{-}$was present, while the Raman intensities of the GT and TT conformers were almost identical when a more kosmotropic anion such as $\mathrm{CH}_{3} \mathrm{COO}^{-}$was present.

To investigate the difference in the partial molar enthalpy between the $T T$ and $G T$ conformers $\left(\Delta H^{T T \rightarrow G T}\right)$, we subsequently measured the temperature dependence of the
Raman spectra of the pure [bmim $]^{+}$-based RTILs. Figure 4 shows representative Raman spectra of pure $[\mathrm{bmim}][X](X=$ $\mathrm{SCN}$ and $\mathrm{NO}_{3}$ ) as a function of temperature. The Raman intensity of the $T T$ conformer increases as the temperature increases for all [bmim $]^{+}$-based RTILs used in this study, while that of the GT conformer decreases. Recently, Endo et al. [5] reported that the Raman intensity of the GT conformer of the $[\mathrm{bmim}]^{+}$cation in pure $[\mathrm{bmim}]\left[\mathrm{PF}_{6}\right]$ decreases with increasing temperature. Holomb et al. [10] also showed that the $G T$ conformer of the $[\mathrm{bmim}]^{+}$cation in pure $[\mathrm{bmim}]\left[\mathrm{BF}_{4}\right]$ decreases with increasing temperature. The present results are qualitatively consistent with the previous results by Endo et al. [5] and Holomb et al. [10].

We can determine $\Delta H^{T T \rightarrow G T}$ of the $[\mathrm{bmim}]^{+}$cation from the temperature dependence of the relative Raman intensities, as shown in Figure 5. Assuming that the ratio of the Raman scattering cross-sections between the conformers $A$ and $B$ is independent of temperature, $\Delta H^{A \rightarrow B}$ is given by (1) [19]

$$
\Delta H^{A \rightarrow B}=-R\left\{\frac{\partial \ln \left(I_{B} / I_{A}\right)}{\partial(1 / T)}\right\}_{p}
$$

In this equation, $R, T$, and $p$ are the gas constant, temperature, and pressure, respectively. $I_{A}$ and $I_{B}$ indicate the relative Raman intensity of conformers $A$ and $B$, respectively, and " $A$ " and " $B$ " correspond to the conformers of the [bmim] $]^{+}$ cation. From the slopes of the lines in Figure 5, $\Delta H^{T T \rightarrow G T}$ is determined to be $-0.9 \pm 0.1 \mathrm{~kJ} / \mathrm{mol}$ for $[\mathrm{bmim}]\left[\mathrm{CH}_{3} \mathrm{COO}\right]$, $-1.1 \pm 0.2 \mathrm{~kJ} / \mathrm{mol}$ for $[\mathrm{bmim}]\left[\mathrm{NO}_{3}\right],-1.5 \pm 0.4 \mathrm{~kJ} / \mathrm{mol}$ for $[\mathrm{bmim}][\mathrm{SCN}]$, and $-1.0 \pm 0.1 \mathrm{~kJ} / \mathrm{mol}$ for $[\mathrm{bmim}]\left[\mathrm{BF}_{4}\right]$, respectively. The $G T$ conformer is enthalpically more stable than the TT conformer for all [bmim $]^{+}$-based RTILs used in this study. A remarkable result is that, considering the standard error, the values of $\Delta H^{T T \rightarrow G T}$ in all [bmim $]^{+}$-based RTILs are approximately $-1.0 \mathrm{~kJ} / \mathrm{mol}$ and are independent of the anionic species. As mentioned in the introduction, Umebayashi et al. [12] reported a detailed thermodynamic 


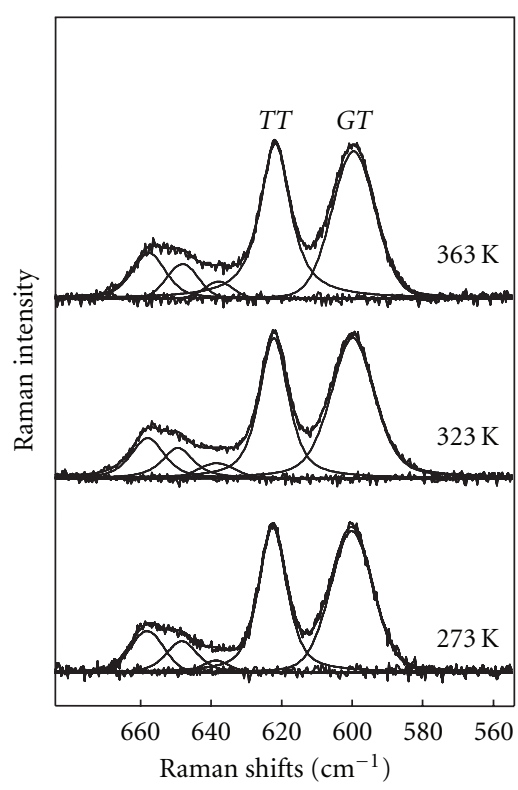

(a) $[\mathrm{bmim}][\mathrm{SCN}]$

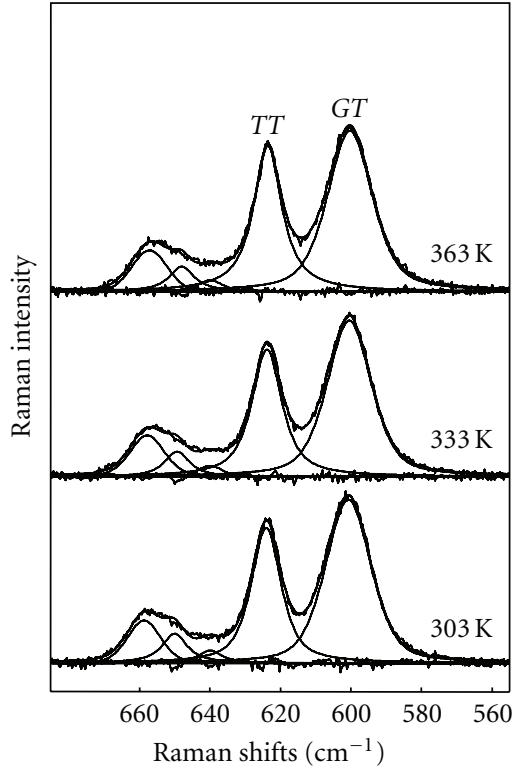

(b) $[$ bmim $]\left[\mathrm{NO}_{3}\right]$

FIGURE 4: Representative Raman $\mathrm{CH}_{2}$ rocking spectra of (a) $[\mathrm{bmim}][\mathrm{SCN}]$ and (b) $[\mathrm{bmim}]\left[\mathrm{NO}_{3}\right]$ as a function of temperature.

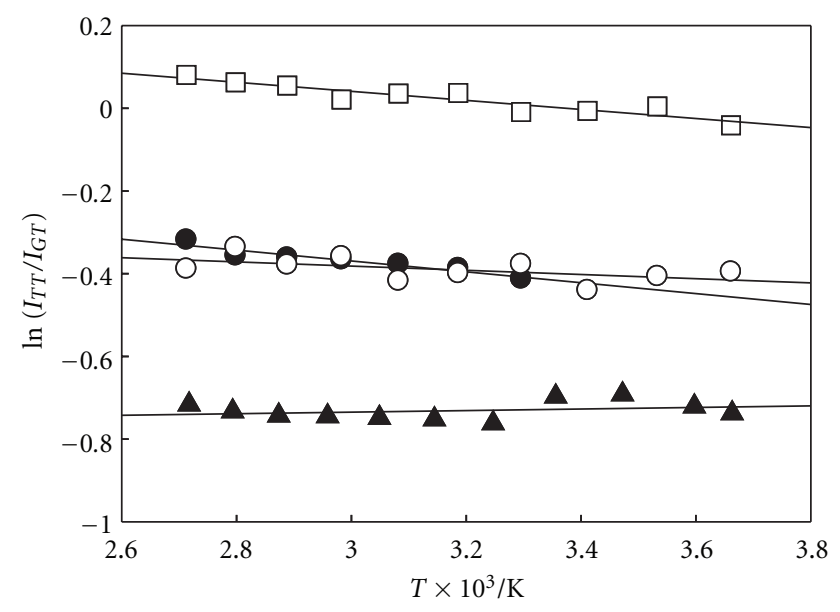

FIGURE 5: Temperature dependences of the integrated intensity ratio between the TT and GT conformers of $[\mathrm{bmim}]^{+}$cation of pure $[\mathrm{bmim}][X]\left(X=\mathrm{BF}_{4}(\boldsymbol{\Delta}), \mathrm{NO}_{3}(\bullet), \mathrm{SCN}(\bigcirc)\right.$, and $\left.\mathrm{CH}_{3} \mathrm{COO}(\square)\right)$. The straight lines represent the result of the least-squares analysis.

analysis of the effect of halide anions $\left(\mathrm{Cl}^{-}, \mathrm{Br}^{-}\right.$, and $\left.\mathrm{I}^{-}\right)$on the conformational equilibrium of the $[\mathrm{bmim}]^{+}$cation. They showed that the population of the GT conformer increases with the decreasing ionic radius of the halide anions $\left(\mathrm{Cl}^{-}\right.$, $\mathrm{Br}^{-}$, and $\mathrm{I}^{-}$) and that $\Delta H^{T T \rightarrow G T}$ changes linearly with the increasing ionic radius of these anions. They concluded that the thermodynamic stability of the GT conformer is due to compensatory effects of the enthalpic (electrostatic interaction) and entropic (configuration) contributions.

On the other hand, our results showed that $\Delta H^{T T \rightarrow G T}$ of the $[\mathrm{bmim}]^{+}$cation is independent of the anionic species studied (all approximately $-1.0 \mathrm{~kJ} / \mathrm{mol}$ ). According to the
Raman study by Jeon et al. [20], the conformational preference of the $[\mathrm{bmim}]^{+}$cation in $[\mathrm{bmim}]\left[\mathrm{BF}_{4}\right]$ is different from that in $[\mathrm{bmim}][\mathrm{I}]$, although the ionic radius of the $\mathrm{BF}_{4}{ }^{-}$ion is just slightly larger than that of the $\mathrm{I}^{-}$ion. They proposed that a slight change in the anion's position would lead to different conformations of the $[\mathrm{bmim}]^{+}$cation. In other words, the conformational preference of the $[\mathrm{bmim}]^{+}$cation in $[\mathrm{bmim}][X]\left(X=\mathrm{BF}_{4}\right.$ and $\left.\mathrm{I}\right)$ relates to the relative orientation of the cation and anion. From the thermodynamic relationship $\Delta G=\Delta H-T \Delta S$, our results imply that the thermodynamic stability of the conformational equilibrium of the $[\mathrm{bmim}]^{+}$cation in $[\mathrm{bmim}]^{+}$-based RTILs including nonspherical anions would be entropy driven. Therefore, we may conclude that the conformational preference of the [bmim $]^{+}$cation and its stability are driven by the entropic contribution (configuration).

However, it is difficult to say more about the conformational stability of the $[\mathrm{bmim}]^{+}$cation in pure $[\mathrm{bmim}]^{+}$-based RTILs, because we cannot directly determine $\Delta G^{T T \rightarrow G T}$ of the $[\mathrm{bmim}]^{+}$cation. Further theoretical calculations, such as MD simulations and large-cluster quantum chemical calculations, may facilitate a greater understanding of the factors contributing to the conformational stability of the $[\mathrm{bmim}]^{+}$cation in these $[\mathrm{bmim}]^{+}$-based RTILs.

In summary, the counteranion effect on the trans-trans (TT) and gauche-trans (GT) equilibrium in 1-butyl-3-methylimidazolium $\left([\mathrm{bmim}]^{+}\right)$-based RTILs has been studied using the Raman spectroscopy. The value of $I_{G T} / I_{T T}$, which is proportional to $\Delta G^{T T \rightarrow G T}$, of the [bmim $]^{+}$cation shows a linear correlation with the Hofmeister series of the anions. On the other hand, the value of the enthalpy change $\left(\Delta H^{T T \rightarrow G T}\right)$ of the $[\mathrm{bmim}]^{+}$cation is approximately $-1.0 \mathrm{~kJ} / \mathrm{mol}$ and is independent of the anionic species. We conclude that the conformational preference of the $[\mathrm{bmim}]^{+}$ 
cation and anions the conformational stability are driven by entropic contributions such as the orientation between the $[\mathrm{bmim}]^{+}$cation and nonspherical anions.

\section{References}

[1] T. Welton, "Room-temperature ionic liquids. Solvents for synthesis and catalysis," Chemical Reviews, vol. 99, no. 8, pp. 2071-2084, 1999.

[2] H. Hamaguchi and R. Ozawa, "Structure of ionic liquids and ionic liquid compounds: are ionic liquids genuine liquids in the conventional sense?" Advances in Chemical Physics, vol. 131, pp. 85-104, 2005.

[3] H. Katayanagi, S. Hayashi, H. Hamaguchi, and K. Nishikawa, "Structure of an ionic liquid, 1-n-butyl-3-methylimidazolium iodide, studied by wide-angle X-ray scattering and Raman spectroscopy," Chemical Physics Letters, vol. 392, no. 4-6, pp. 460-464, 2004.

[4] M. Imanari, M. Nakakoshi, H. Seki, and K. Nishikawa, " ${ }^{1} \mathrm{H}$ NMR study on reorientational dynamics of an ionic liquid, 1-butyl-3-methylimidazolium bromide, accompanied with phase transitions," Chemical Physics Letters, vol. 459, no. 1-6, pp. 89-93, 2008.

[5] T. Endo, T. Kato, K. Tozaki, and K. Nishikawa, "Phase behaviors of room temperature ionic liquid linked with cation conformational changes: 1-Butyl-3-methylimidazolium hexafluorophosphate," Journal of Physical Chemistry B, vol. 114, no. 1, pp. 407-411, 2010.

[6] R. W. Berg, "Raman spectroscopy and ab-initio model calculations on ionic liquids," Monatshefte für Chemie, vol. 138, no. 11, pp. 1045-1075, 2007.

[7] R. Ozawa, S. Hayashi, S. Saha, A. Kobayashi, and H. Hamaguchi, "Rotational isomerism and structure of the 1-butyl-3methylimidazolium cation in the ionic liquid state," Chemistry Letters, vol. 32, no. 10, pp. 948-949, 2003.

[8] Y. Umebayashi, T. Fujimori, T. Sukizaki et al., "Evidence of conformational equilibrium of 1-ethyl-3-methylimidazolium in its ionic liquid salts: Raman spectroscopic study and quantum chemical calculations," Journal of Physical Chemistry A, vol. 109, no. 40, pp. 8976-8982, 2005.

[9] N. E. Heimer, R. E. Del Sesto, Z. Meng, J. S. Wilkes, and W. R. Carper, "Vibrational spectra of imidazolium tetrafluoroborate ionic liquids," Journal of Molecular Liquids, vol. 124, no. 1-3, pp. 84-95, 2006.

[10] R. Holomb, A. Martinelli, I. Albinsson, J. C. Lassègues, P. Johansson, and P. Jacobsson, "Ionic liquid structure: the conformational isomerism in 1-butyl-3-methyl-imidazolium tetrafluoroborate ([bmim] $\left.\left[\mathrm{BF}_{4}\right]\right)$," Journal of Raman Spectroscopy, vol. 39, no. 7, pp. 793-805, 2008.

[11] Y. U. Paulechka, G. J. Labo, and V. N. Emel'yanenko, “Structure, conformations, vibrations, and ideal-gas properties of 1alkyl-3-methylimidazolium bis(trifluoromethylsulfonyl)imide ionic pairs and constituent ions," Journal of Physical Chemistry B, vol. 112, no. 49, pp. 15708-15717, 2008.

[12] Y. Umebayashi, H. Hamano, S. Tsuzuki et al., "Dependence of the conformational isomerism in 1-n-butyl-3-methylimidazolium ionic liquids on the nature of the halide anion," Journal of Physical Chemistry B, vol. 114, no. 36, pp. 1171511724, 2010.

[13] J. N. A. C. Lopes and A. A. H. Pádua, "Using spectroscopic data on imidazolium cation conformations to test a molecular force field for ionic liquids," Journal of Physical Chemistry B, vol. 110, no. 14, pp. 7485-7489, 2006.
[14] T. Takekiyo, Temperature and pressure effects on the conformational equilibria of model compounds of proteins in aqueous solutions: a vibrational spectroscopy, Ph.D. thesis, Ritumeikan Univerisity, Shiga, Japan, 2005.

[15] F. Hofmeister, "Zur Lehre von der Wirkug der Salze," Archiv for Experimentelle Pathologie und Pharmakologie, vol. 24, pp. 247-269, 1888.

[16] Y. Zhang and P. S. Cremer, "Interactions between macromolecules and ions: the Hofmeister series," Current Opinion in Chemical Biology, vol. 10, no. 6, pp. 658-663, 2006.

[17] H. Zhao, O. Olubajo, Z. Song et al., "Effect of kosmotropicity of ionic liquids on the enzyme stability in aqueous solutions," Bioorganic Chemistry, vol. 34, no. 1, pp. 15-25, 2006.

[18] W. Kunz, P. Lo Nostro, and B. W. Ninham, "The present state of affairs with Hofmeister effects," Current Opinion in Colloid and Interface Science, vol. 9, no. 1-2, pp. 1-18, 2004.

[19] T. Takekiyo, M. Kato, and Y. Taniguchi, "FT-IR spectroscopic study on conformational equilibria of $[\mathrm{Leu}]^{5}$-enkephalin in DMSO and ${ }^{2} \mathrm{H}_{2} \mathrm{O}$ solutions," Journal of Molecular Liquids, vol. 119, no. 1-3, pp. 147-152, 2005.

[20] Y. Jeon, J. Sung, C. Seo et al., "Structures of ionic liquids with different anions studied by infrared vibration spectroscopy," Journal of Physical Chemistry B, vol. 112, no. 15, pp. 47354740, 2008. 


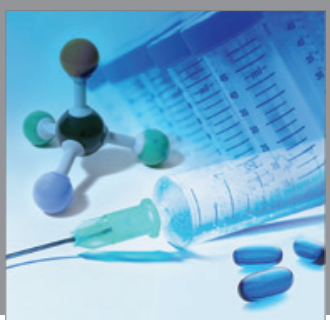

International Journal of

Medicinal Chemistry

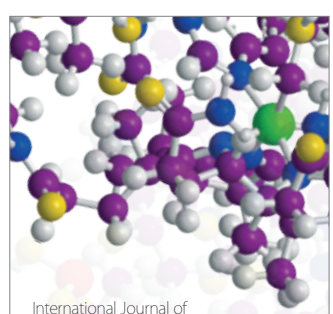

Carbohydrate Chemistry

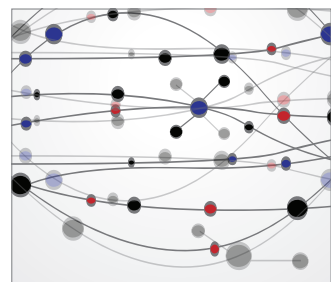

The Scientific World Journal
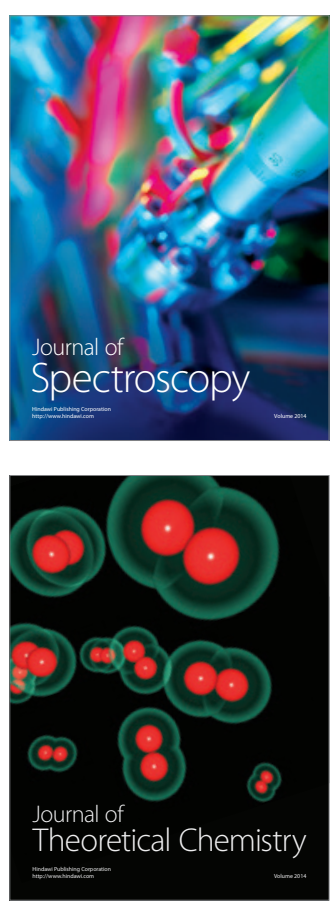
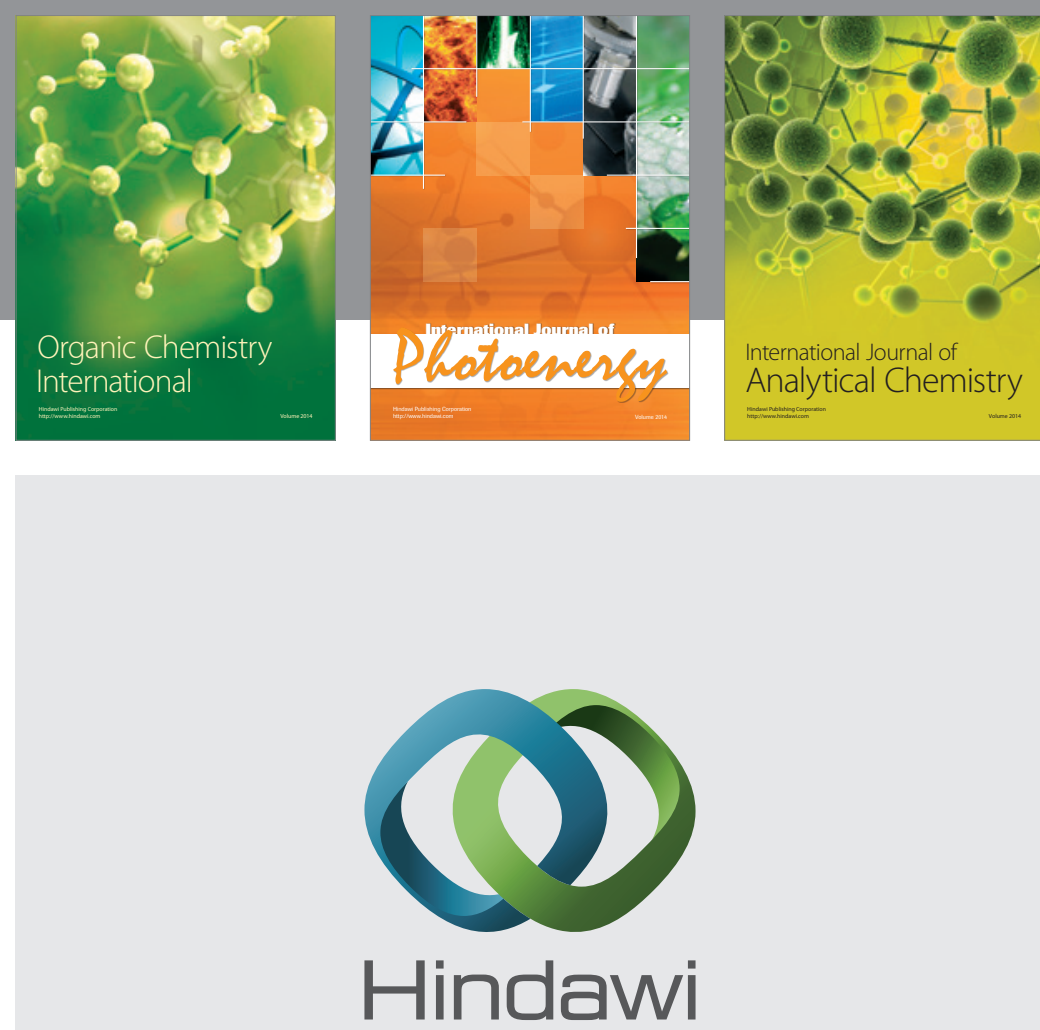

Submit your manuscripts at

http://www.hindawi.com
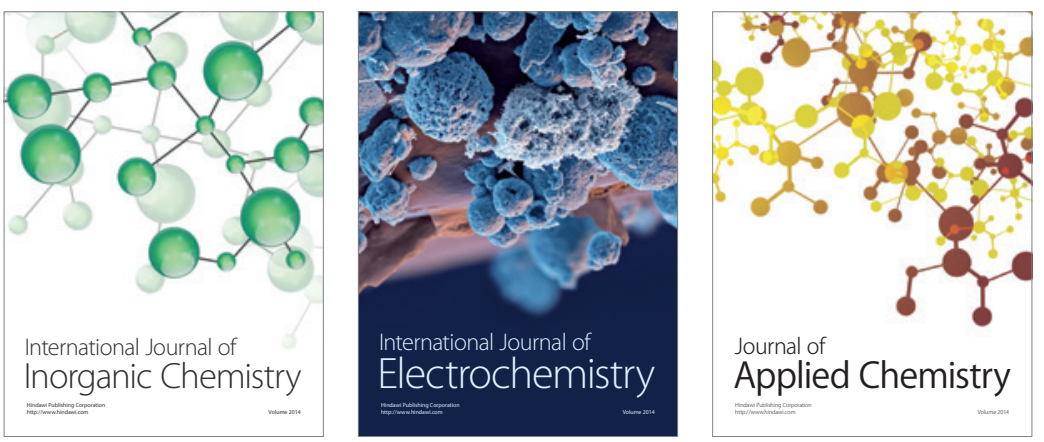

Journal of

Applied Chemistry
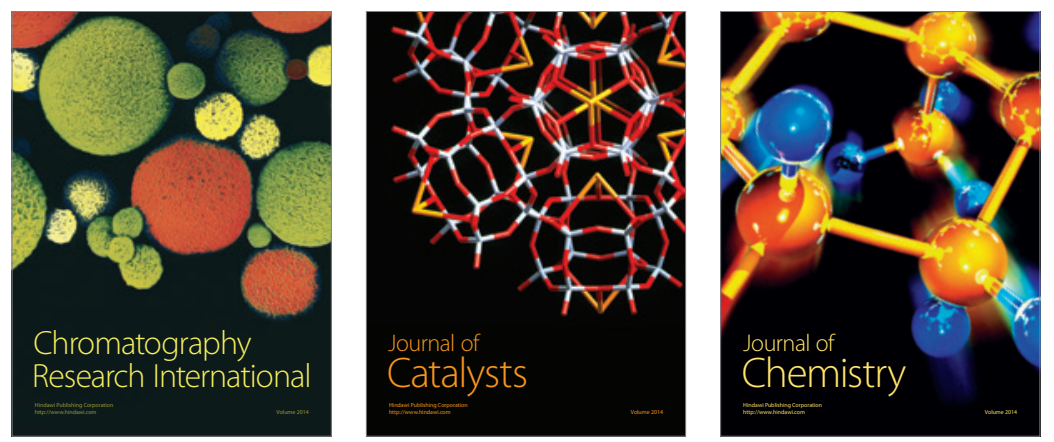
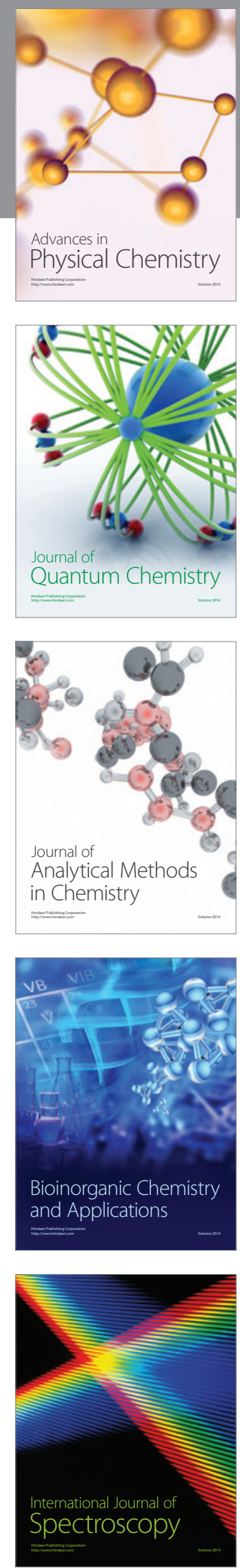